\title{
Large outbreak of Salmonella Thompson related to smoked salmon in the Netherlands, August to December 2012
}

I Friesema (ingrid.friesema@rivm.nl) ${ }^{1,2}$, A de Jong ${ }^{2,3}$, A Hofhuis ${ }^{1,2}$, M Heck $^{4}$, H van den Kerkhof ${ }^{5}$ R de Jonge ${ }^{6}$, D Hameryck ${ }^{3}$,

$\mathrm{K} \mathrm{Nagel}^{3}$, G van Vilsteren ${ }^{3}$, P van Beek ${ }^{5}$, D Notermans ${ }^{4}$, W van Pelt ${ }^{1}$

1. Epidemiology and Surveillance Unit, Centre for Infectious Disease Control, National Institute for Public Health and the Environment (RIVM), Bilthoven, the Netherlands

2. These authors contributed equally to this work

3. Dutch Food and Consumer Product Safety Authority (NVWA), Utrecht, the Netherlands

4. Laboratory for Infectious Diseases and Perinatal Screening, Centre for Infectious Disease Control, RIVM, Bilthoven, the Netherlands

5. Preparedness and Response Unit, Centre for Infectious Disease Control, RIVM, Bilthoven, the Netherlands

6. Centre for Zoonoses and Environmental Microbiology, Centre for Infectious Disease Control, RIVM, Bilthoven, the Netherlands

Citation style for this article:

Friesema I, de Jong A, Hofhuis A, Heck M, van den Kerkhof H, de Jonge R, Hameryck D, Nagel K, van Vilsteren G, van Beek P, Notermans D, van Pelt W. Large outbreak of Salmonella Thompson related to smoked salmon in the Netherlands, August to December 2012. Euro Surveill. 2014;19(39):pii=20918. Available online: http:// www.eurosurveillance.org/ViewArticle.aspx?Articleld=20918

Article submitted on 20 June 2013 / published on 2 October 2014

On 15 August 2012, an increase in the number of Salmonella Thompson cases was noticed by the Salmonella surveillance in the Netherlands. A casecontrol study was performed, followed by a food investigation. In total 1,149 cases were laboratoryconfirmed between August and December 2012 of which four elderly (76-91 years) were reported to have died due to the infection. The cause of the outbreak was smoked salmon processed at a single site. The smoked salmon had been continuously contaminated in the processing lines through reusable dishes, which turned out to be porous and had become loaded with bacteria. This is the largest outbreak of salmonellosis ever recorded in the Netherlands. The temporary closure of the processing site and recall of the smoked salmon stopped the outbreak. An estimated four to six million Dutch residents were possibly exposed to the contaminated smoked salmon and an estimated 23,000 persons would have had acute gastroenteritis with $S$. Thompson during this outbreak. This outbreak showed that close collaboration between diagnostic laboratories, regional public health services, the national institute for public health and the food safety authorities is essential in outbreak investigations.

\section{Introduction}

In the Netherlands, an estimated 35,000 cases of salmonellosis occurred in 2009, which equals around 212 cases per 100,000 inhabitants [1]. Overall, based upon data from the Dutch laboratory surveillance network for gastroenteric pathogens, the incidence of salmonellosis in the Netherlands has decreased since 1997, with some peaks due to outbreaks [2]. Almost every year, 15 to 20 outbreaks of salmonellosis are detected at a regional or national level. The largest outbreaks recorded in the Netherlands up to the time of this report, were an excess of 540 confirmed cases of Salmonella Enteritidis in 2003 most likely caused by increased importation of contaminated eggs, during the avian influenza outbreak [3]; and an outbreak of S. Typhimurium phage type 561 with 224 laboratoryconfirmed cases due to contaminated hard, raw milk cheese in 2006 [4]. Whereas S. Typhimurium together with $S$. Enteritidis are the most common serotypes responsible for salmonellosis in the Netherlands, infections with $S$. Thompson are rare with zero to seven cases per year laboratory-confirmed within the laboratory surveillance network in the past ten years [2]. In the literature, the number of reports on outbreaks due to $S$. Thompson are limited with distinct implicated sources as cilantro [5], rucola lettuce [6], bread contaminated by an ill food handler [7], roast beef [8], egg albumen [9], and cow's milk [9].

On 15 August 2012 (week 33), the National Institute for Public Health and the Environment (RIVM) noticed an increase in the number of $S$. Thompson cases in the Dutch laboratory surveillance network. That week, 11 cases and two weeks earlier four cases were detected at the RIVM, scattered over the country. This prompted an outbreak investigation to identify the source, in order to take subsequent actions to prevent further cases. In October 2012, as the outbreak was ongoing, a preliminary report was published [10]. In this final report, all available data were combined to describe the complete outbreak.

\section{Methods}

\section{Laboratory surveillance network}

The Dutch laboratory surveillance network, established in 1987 , is based on 16 regional public health laboratories, which send Salmonella isolates from patients to the RIVM for further typing, covering ca $64 \%$ of the 
Dutch population [11]. Each isolate is accompanied by a standardised completed request form with information about the submitting laboratory, basic demographics of the patient and the isolate. At the RIVM, the isolates are serotyped and the results and background information are filed in the laboratory registry system. Additionally, during this outbreak, Dutch diagnostic laboratories outside the surveillance network, were encouraged to submit Salmonella group C isolates, to which $S$. Thompson belongs, in order to get a more complete picture of the outbreak.

\section{Epidemiological investigation}

Cases were defined as residents of the Netherlands with an $S$. Thompson isolate cultured from any sample type, confirmed at the RIVM between August and December 2012. Between 16 August (week 33) and 28 September (week 39) when the source was identified, the regional public health services were requested once a week to contact the new cases of that week within their region after obtaining consent from the doctor in attendance, to administer an extensive questionnaire. This questionnaire covered consumption of different meats, fish, dairy products, vegetables and fruits, snacks, establishments where food was purchased, contact with a person with diarrhoea and contact with animals during the seven days before onset of illness. Furthermore, information about the symptoms, onset of illness and hospitalisation was asked. An adapted questionnaire was also sent to controls from the general population in the same period (week 33-39). From the database with a random sample of the Dutch population available at the RIVM, four controls from the same or neighbouring municipality with comparable year of birth, and sex were drawn. The control questionnaire was sent by mail. An envelope with a freepost number was included to return the questionnaire.

On 28 September (week 39) the source was found, namely smoked salmon, and a recall was started to remove the product from the market. As the number of submitted isolates kept rising after the recall, a supplemental study was performed between 19 October and 22 November (week 42-47), in order to monitor the course of the outbreak and to check whether smoked salmon was still the cause. Cases with a first date of illness after 5 October 2012 (more than one week after the start of the recall) or unknown onset of illness were contacted with a short questionnaire. The cases were asked when they fell ill, whether they had eaten fish or seafood and if so, where they had bought or eaten it, when, and what type of fish or seafood. Cases were also requested to indicate whether they had been in contact with another patient with similar symptoms in the week before falling ill.

\section{Food and trace-back investigations}

The Dutch Food and Consumer Product Safety Authority (NVWA), which is responsible for product tracing during foodborne outbreaks in the Netherlands, performed a trace-back investigation based on the results of the case-control study. Subsequently, samples were taken at the processing site of a Dutch producer of smoked salmon that emerged from this investigation as a likely source of the outbreak.

\section{Microbiological investigation}

Salmonella isolates submitted to the RIVM were serotyped based on $\mathrm{O}$ - and $\mathrm{H}$-group antigens according to the World Health Organization (WHO) Collaborating Centre for Reference and Research on Salmonella [12]. A subset of isolates of Salmonella enterica subsp. enterica Thompson from patients and food samples were subjected to molecular typing by means of pulsed-field gel electrophoresis (PFGE) according to the PulsNet International protocol [13]. Restriction enzyme $X b a /$ was used for digestion of DNA. The banding patterns, i.e. DNA fingerprints, were compared using BioNumerics 6.6 (Applied Maths, Sint-Martens-Laten, Belgium) with tolerance and optimisation both set at $1 \%$. To confirm our PFGE analysis, strains were sent to Centers for Disease Control and Prevention (CDC) in Atlanta for DNA fingerprinting.

\section{International inquiry}

An urgent inquiry was sent out by the RIVM on 23 August 2012 to European Union (EU) Member States via the Epidemic Intelligence Information System (EPIS), managed by the European Centre for Disease Prevention and Control (ECDC). Member States were asked to report any increase in the number of cases of $S$. Thompson in their countries. On 1 October a notice was sent to all National Focal Points in Europe via the Early Warning and Response System (EWRS).

\section{Statistical analyses}

All statistical analyses were performed using SAS 9.2 (SAS institute Inc., USA). In the case-control analysis, variables with a $p$-value of less than 0.20 in the univariate logistic regression were entered into the multivariate analysis. A final model was determined by backward elimination of variables, until all variables in the model had reached significance ( $p<0.05$ ), adjusted for age and sex, and the model was significant. Day of onset was mainly available for the cases completing the extensive questionnaire or the supplemental questionnaire, and only rarely for the other cases via the form accompanying the Salmonella isolate presented for serotyping. The epidemic curve of the frequencies of cases by dates of onset was biased, as the questionnaires were completed at the beginning of the outbreak (extensive questionnaire) or at the end of the outbreak (supplemental questionnaire). Therefore, for cases without known day of onset but with a date of sampling, an estimated day of onset was calculated based on the median number of days between date of onset and sampling for the cases in the same period (whereby the time of the outbreak was divided in three periods: beginning, middle and end). This time span between onset and sampling was estimated using data from cases with both dates available. 


\section{Results}

\section{Descriptive epidemiology}

In total 1,149 cases were laboratory-confirmed at the RIVM between August and December 2012 of which 812 within the national surveillance network laboratories and 337 within Dutch diagnostics laboratories outside the surveillance network, which had been encouraged to submit Salmonella group C isolates. Two men and two women aged between 76 and 91 years were reported to have died due to the $S$. Thompson infection. The Figure shows the epidemic curve according to reported and estimated day of disease onset. The first isolates of the outbreak arrived at the RIVM on 27 July (week 30), and the last isolates arrived on 27 and 28 December (week 52). Serotyping at the RIVM lasted between two and 21 days (median seven days), although the preliminary results (before being checked and made available by RIVM) were frequently ready up to two days earlier than the median seven days. The peak of isolate entries was in week 41. Reported dates of disease onset ranged from 20 June to 10 November with a peak in week 40 . However, when an estimation of the date of onset for the cases without a known date of illness onset was also taken into account, the peak shifted to week 39.

For the 1,079 outbreak cases for which sex was known, $696(65 \%)$ were female (Table 1). Age information was available for all cases $(n=1,149)$ and the median age was 45 years (range: 0-95 years). For comparison, the median age of the other 1,624 cases of salmonellosis reported to the RIVM in 2012 was 29 years, and $53 \%$ were female. Strikingly, five outbreak cases were younger than six months and thus most likely not eating solid foods yet, three of them had family members with a confirmed infection. The youngest case was two days-old when tested, and was most likely infected during birth as the mother also tested positive. The mother of another baby who had become ill at the age of one month, had been positive two days before giving birth. A three-month-old baby had a 23-monthold sister who was ill. Another nine family clusters could be identified among the 1,149 confirmed cases: mother-child $(n=3)$, siblings $(n=3)$ and partners $(n=3)$. In the extensive questionnaire, $7 \%(8 / 112)$ reported to have had contact with a person with diarrhoea in the week before falling ill. In the supplemental study, this question was added later with seven cases of 27 having had such contact.

The extensive questionnaire was completed by 112 respondents (response 63\%). As expected, diarrhoea was the most important symptom (108/112, 96\%; Table 2) with a median duration of seven days (range: 1-21 days). About one-quarter of the cases (29/104) recorded blood in their stool. Fever $\left(38.0^{\circ} \mathrm{C}\right)$ was mentioned by $63(62 \%)$ of 101 cases, and 39 of 112 cases (35\%) were hospitalised for a median of four days (range: 1-15 days). The median age of the hospitalised cases was 70 years (range: 7-91 years).

\section{FIGURE}

Number of Salmonella Thompson outbreak cases according to reported and estimated day of disease onset, the

Netherlands, 18 June-30 December $(n=1,027)^{\mathrm{a}}$

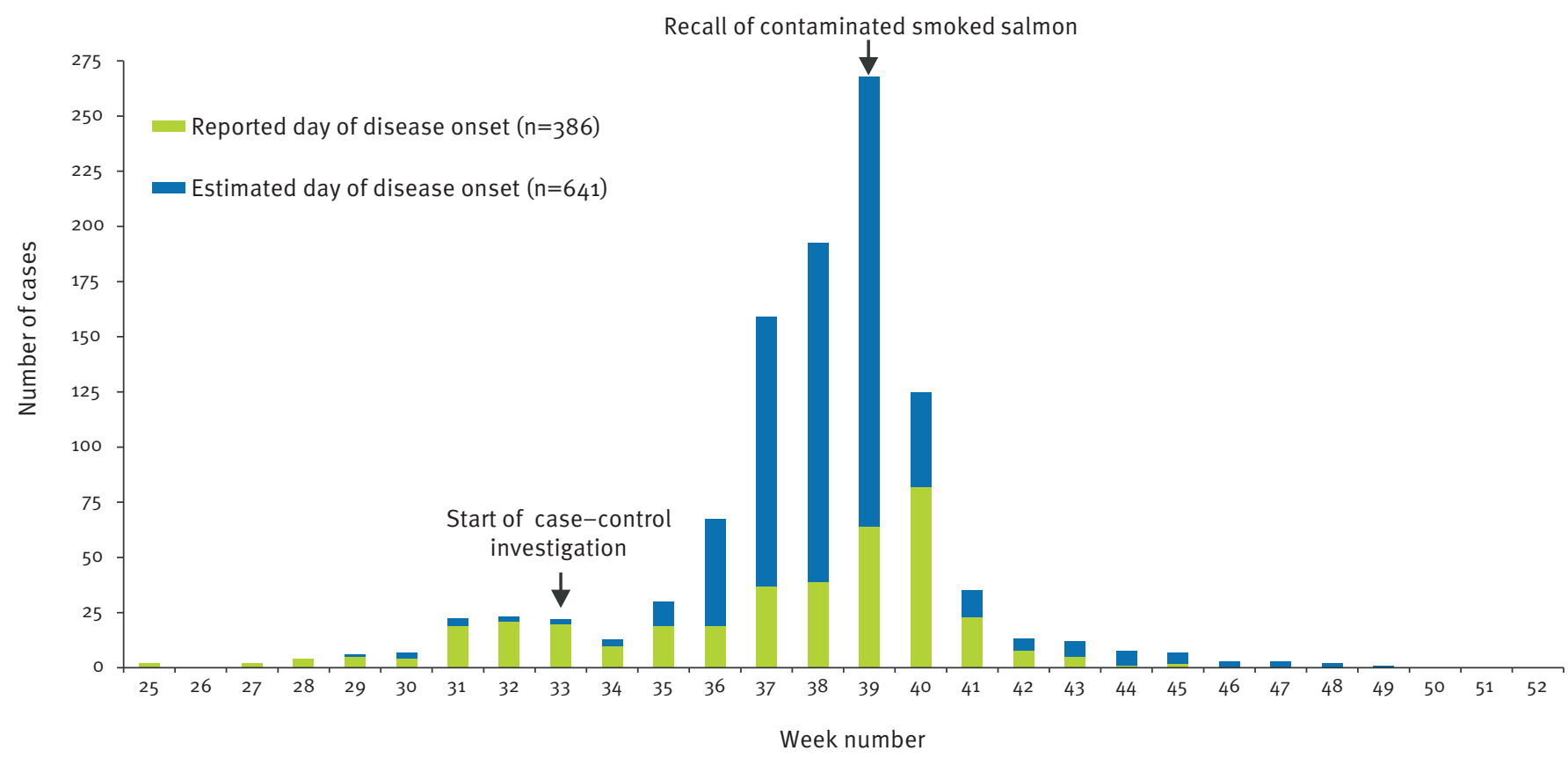

Although a total of 1,149 laboratory-confirmed cases were part of the outbreak, only 1,027 are depicted in this Figure because for 122 cases the day of disease onset could not be determined due to missing information. 
For cases with known dates of illness onset and sampling, the delay between date of onset and sampling for diagnostics appeared to increase during the outbreak, especially toward the end (Table 3). The time between sampling and arrival of the isolate at the RIVM remained stable with a median of seven days, and $98 \%$ (967/983) within 14 days. Consecutive second and third positive isolates were sent in at a later point in time for 43 cases and three cases, respectively. When excluding the cases with the second sampling on the same day as the first sampling, median number of days between both sampling moments was nine days, with a range of 1 to 76 days ( $n=30$ cases). Twenty-one cases of which repeated samples were submitted were 55 years of age or older. Information on hospitalisation was available for seven of these cases, and all seven were admitted to hospital.

\section{Case-control study}

Every time completed questionnaires were returned, the case-control statistical analysis was repeated, and results of possible outbreak sources were communicated with the NVWA. Analyses indicated several potential sources, namely minced meat (10 September), ready-to-eat raw vegetables (17 September), ice cream (18 September) and smoked fish (24 September). Another result of the analyses was that cases more frequently reported to shop at certain supermarket chains affiliated with one purchasing coordinating organisation. The odds ratio (OR) for smoked fish was 6.4 (95\% confidence interval $(\mathrm{Cl}): 3.3-12.5)$ in the final multivariate analysis with all available questionnaires (108

\section{TABLE 1}

Characteristics of the reported Salmonella Thompson outbreak cases, the Netherlands, August-December 2012 $(\mathrm{n}=1,149)$

\begin{tabular}{|c|c|}
\hline Characteristics of cases & N (\%) \\
\hline \multicolumn{2}{|l|}{ Sex ${ }^{a}$} \\
\hline Female & $696(65)^{a}$ \\
\hline Male & $383(35)^{a}$ \\
\hline Unknown & $70(6)$ \\
\hline \multicolumn{2}{|l|}{ Age group in years ${ }^{b}$} \\
\hline $0-9$ & $124(11)$ \\
\hline $10-19$ & $173(15)$ \\
\hline $20-29$ & $154(13)$ \\
\hline $30-39$ & $75(7)$ \\
\hline $40-49$ & $94(8)$ \\
\hline $50-59$ & $147(13)$ \\
\hline $60-69$ & $165(14)$ \\
\hline $70-79$ & $130(11)$ \\
\hline$\geq 80$ & $87(8)$ \\
\hline
\end{tabular}

a The percentages of males and females are calculated from the 1,079 cases, for which Information on sex was available.

b The age of all cases was known and the median age of cases was 45 years (range: $0-95$ ). cases and 198 controls). Fifty-seven per cent of the cases reported consumption of smoked fish (62/108), mostly smoked salmon, compared to 52 of 198 (26\%) of the controls. Other risk factors were buying at supermarket chains affiliated with the purchasing organisation (OR: 3.5; 95\% CI: 1.9-6.8), buying at supermarket chain A (OR: $2.3 ; 95 \% \mathrm{Cl}: 1.2-4.5)$, and consumption of ready-to-eat raw vegetables (OR: $3.3 ; 95 \% \mathrm{Cl}: 1.3-8.4$ ) and ice cream (OR: $2.3 ; 95 \% \mathrm{Cl}: 1.2-4.7$ ). No significant interaction terms were found between the supermarkets and the food products.

\section{Food and trace-back investigations}

The NVWA followed up each of the four possible sources identified by the case-control study. Where possible, supermarkets and patients were contacted and food samples were taken. Ready-to-eat vegetables were quickly ruled out, as they included a large variety of vegetables from many different sources and producers. The purchasing organisation informed the NVWA that ice cream and vegetables were not procured at one single producer. However, when the case-control analysis pointed toward smoked fish consumption, particularly smoked salmon, the purchasing organisation indicated that all smoked salmon originated from

\section{TABLE 2}

Symptoms and hospitalisation as reported by Salmonella Thompson outbreak cases in the extensive questionnaire, the Netherlands, August-December $2012(\mathrm{n}=112)$

\begin{tabular}{|l|c|}
\hline Characteristic & $\mathrm{n} / \mathrm{N}^{\mathrm{a}}(\%)$ \\
\hline Diarrhoea & $108 / 112(96)$ \\
\hline Blood in stool & $29 / 104(28)$ \\
\hline Nausea & $67 / 112(60)$ \\
\hline Vomiting & $44 / 111(40)$ \\
\hline Abdominal pain & $88 / 111(79)$ \\
\hline Fever $\left(>38.0^{\circ} \mathrm{C}\right)$ & $63 / 101(62)$ \\
\hline Tremors & $58 / 101(57)$ \\
\hline Hospitalisation & $39 / 112(35)$ \\
\hline
\end{tabular}

a Some symptoms were not reported by all the questionnaire respondents.

\section{TABLE 3}

Days between date of illness onset and date of sampling, Salmonella Thompson outbreak, the Netherlands, AugustDecember $2012(n=340)$

\begin{tabular}{|l|c|l|}
\hline $\begin{array}{l}\text { Period within } \\
\text { the outbreak }\end{array}$ & $\begin{array}{c}\text { Number } \\
\text { of cases }\end{array}$ & $\begin{array}{l}\text { Median time between date of illness } \\
\text { onset and date of sampling (range) }\end{array}$ \\
\hline Week $31-37^{\mathrm{a}}$ & 74 & 5 days (o-80 days) \\
\hline Week $38-43^{\mathrm{a}}$ & 234 & 5 days (o-92 days) \\
\hline Week $44-52^{\mathrm{a}}$ & 32 & 17 days (0-83 days) \\
\hline
\end{tabular}

a Refers to the week number in 2012 in which the isolate arrived at the National Institute for Public Health and the Environment (RIVM). 
one Dutch producer. Supermarket chain A also bought a part of its smoked salmon at the same producer as the purchasing organisation. The day after this finding, 26 September, the NVWA visited the Dutch fish producer and collected samples from different batches of smoked salmon products, as did the fish producer. $S$. Thompson was detected by the NVWA in four of nine sampled batches. Subsequently, all smoked salmon from this producer was recalled, starting Friday 28 September (week 39) and a public warning was published. A trace-back analysis by the fish producer showed that the positive batches all were produced on certain production lines in the Greek processing plant of this company. There, the fish is processed before being transported to the Netherlands for further distribution. In week 40, other products containing possibly contaminated smoked salmon, such as readyto-eat salads, were also recalled. Information given by the producer also indicated that smoked salmon was exported to countries in Europe, North America and Central America. An alert was sent out on 1 October via the Rapid Alert System for Food and Feed (RASFF; 2012.1382) to inform these countries of the recall and the ongoing outbreak. This notification did not lead to reports of cases. Furthermore, the Greek authorities (EFET: Helenic Food Authority) were informed about the problem in the Greek production facility of the Dutch fish producer. Based on this alert notification and additional information, EFET temporarily closed the Greek production site of the Dutch fish producer (3-11 October). After analysis of the production process in Greece, the Dutch producer concluded, that the continuing contamination of smoked salmon must have been caused by cross contamination from dishes on which the salmon was transported within the processing lines. These reusable dishes were the most recent main adaptation in the production process and where known to be porous. The dishes were introduced in the production process in Greece in February 2012. Indeed, research conducted by the fish producer showed that the inner layer of the dishes appeared to be filthy and was contaminated with bacteria, including Salmonella. Additional research conducted by the Netherlands Organisation for Applied Scientific Research (TNO) showed that the inner layer of the dishes was highly porous and absorbing the Salmonella [14]. How the dishes initially got contaminated remains unknown.

\section{Supplemental study}

Between week 42 and 47 , a total of 178 cases presented with first date of illness either after 5 October $2012(n=14)$ or unknown $(n=164)$, according to the laboratory request form. The regional public health services contacted these cases with the short questionnaire asking for date of disease onset, fish consumption and possible contact with an ill person with similar symptoms: 87 cases reported a date of illness before 5 October, 43 cases had a date of onset after 5 October, and for 48 cases it remained unknown. For 29 of the 43 cases, consumption of contaminated salmon purchased before the recall or contact with another
S. Thompson case was known or likely. For the remaining cases, the information was insufficient or did not point in the direction of salmon or contact with another $S$. Thompson case; these cases were mostly younger than 10 years $(n=6)$ or older than 70 years $(n=5)$ of age. The results of this supplemental study did not indicate that any contaminated salmon remained on the market or that another source was contributing to the outbreak. Furthermore, the number of new cases per week decreased steadily during these weeks.

\section{Microbiological investigation}

The majority $(93 \%, n=1,064)$ of first positive samples from cases were faeces samples. Other sources were urine $(50 ; 4 \%)$, blood $(24 ; 2 \%)$, and other or unknown (11; $1 \%)$. PFGE was done for isolates of 60 outbreak cases, 16 salmon samples and five non-related strains of previous years. All outbreak strains and salmon isolates presented the same pattern. This finding was confirmed by the typing laboratory of CDC in Atlanta. The strains belonged to pulse type JP6X01.0001. The non-related strains of $S$. Thompson showed a different pattern.

\section{International inquiry}

Eighteen EU Member States responded to the urgent inquiry and reported no significant increase. Three countries reported cases with a PFGE pattern matching the current outbreak strain prior to this outbreak. One of them was a Scandinavian outbreak of $S$. Thompson in 2004 caused by rucola salad [6]. Furthermore, Sweden reported one domestic case and Germany reported three domestic cases with a PFGE pattern similar to the outbreak strain and dates of illness onset during the outbreak, but without a link to the Netherlands or salmon. A Belgian truck driver with an $S$. Thompson infection who had been in the Netherlands several times in the week before falling ill, probably got infected in the Netherlands. At the same time, a cluster of $S$. Thompson infections was investigated in the United States (US) (personal communication, Dr Laura Gieraltowski and Dr Peter Gerner-Smidt, CDC, US; October 2012 and April 2013). No particular exposure was identified. First microbiological results indicated a similar PFGE pattern, but later significant differences between the strains were detected by whole genome sequencing. No connection was found between these concurrent outbreaks.

\section{Discussion}

This outbreak of $S$. Thompson is the largest outbreak of salmonellosis ever recorded in the Netherlands, with 1,149 confirmed cases. However, this number is likely to present only the tip of the iceberg. Dutch population studies provided the multipliers to estimate total numbers of Salmonella cases based on the cases sent in by the laboratories within the Dutch laboratory surveillance network $[1,11]$. Knowing that 812 outbreak cases were submitted within this network, an estimated 23,000 persons would have had acute gastroenteritis with $S$. Thompson in the general population, of which 
650 would have been hospitalised and ca 24 persons may have died from this infection within two years after their infection.

Although a case-control study was started immediately after detection of the outbreak, it took several weeks before the cause could be identified. The main reason for the delay in identifying the source was the low number of cases in the beginning of the outbreak and consequently the low number of completed questionnaires, both from cases and controls, available for analysis. A number of other possible sources were suggested before the analysis led to salmon. This was most likely caused by the relatively low number of cases reporting consumption of smoked fish (62/108, $57 \%)$. This can be due to recall bias, but also because the salmon was incorporated in other products, for example pre-sale ready-to-eat salads or as part of a menu in the catering industry.

The incriminated producer had a large market share for smoked salmon. Based upon information provided by randomly selected respondents in a survey conducted among the general population done by the Epidemiology and Surveillance Unit of the RIVM, 47\% of the Dutch population consumed smoked salmon in a four weeks period (data not shown). Considering a market share of 50 to $80 \%$ for the company, 3.9 to 6.2 million Dutch residents would have been possibly exposed to contaminated smoked salmon in four weeks' time. The reach of one product of one producer with a high market share is huge with consequently large possible implications for the 16 million Dutch population.

Research into the specific origin of the contamination within the processing site in this outbreak proved to be difficult. In the Netherlands, the NVWA is the legal body to perform such source investigation, and is authorised to take active measures in case a source is detected. However, their mandate is limited to the Netherlands and the contaminated production site was in Greece. Via the RASFF system, the NVWA informed the Greek authorities about the problem in the Greek production site of the Dutch fish producer. However, information from the Greek investigation was scarcely available during the Dutch outbreak investigation, thus it was a challenge for the NVWA to quickly reconstruct in an objective way what had gone wrong in the production process in Greece. No objective information was available on whether the contamination possibly had spread through (other) production processes in Greece or to the Dutch production site. The NVWA mostly relied on information provided by the fish producer. Many important details have been published in a study of the Dutch safety board (Onderzoeksraad voor Veiligheid [14]) and are included in this paper. However, it must be noted that some of the information known to the NVWA cannot be disclosed due to judicial restrictions, and thus cannot be presented here.
The smoked salmon in the production line had been continuously contaminated through reusable dishes in the production process, which turned out to be porous and became loaded with bacteria, as the cleaning and disinfecting regime turned out to be not sufficient to kill bacteria on the inside of the plates. In the report of the Dutch safety board [14] data are presented on the trend lines of the number of Enterobacteriaceae in the production process in the Greek production facility, as measured by the fish producer. These data show a small, but not disquieting increase in Enterobacteriaceae levels after implementing the reusable dishes; between June and the end of September, when the source of the outbreak was found, the trend line started to strongly fluctuate. The fluctuation was caused by the alternating growth of bacteria in the production process followed by extra cleaning procedures. Circumstances in Greece were favourable for Salmonella to proliferate. First, the bacteria were present in the inside of the porous reusable dishes, out of range of the cleaning and disinfection procedures. Second, the temperature in the non-refrigerated storing room was running up during the hot Greek summer, reaching values favourable for outgrowth of Salmonella. However, how the first dish got contaminated remains unknown. The reused dishes were introduced in the production process in Greece in February 2012, and were immediately replaced by single-use dishes after being identified as the source of the contamination. A remarkable feature in the epidemic curve is the relative stable number of cases falling ill up to week 35 , before the steep increase. This supports the hypothesis that the level of contamination at the production site was low at the onset, increasing over time and at a certain point in time increased exponentially. However, the outbreak received more attention as it progressed. Before the recall of the smoked salmon, knowledge of the outbreak was mostly limited to the professionals involved in the outbreak response, but the outbreak received a considerable amount of media attention after the recall. This probably led to more patients visiting their physician, physicians requesting more laboratory testing and more laboratories apart from the surveillance laboratories submitting strains, which all could have affected the epidemic curve. The increase of time lag between date of onset and sampling date at the end of the outbreak is supportive for this.

The peak of cases, based upon date of onset, was in week 39 with a rapid decline in the number of cases afterwards. As the recall of smoked salmon started at the end of week 39 , it is very plausible that the decline in cases is the result of this recall. As the number of cases was increasing rapidly in the weeks prior to the recall, it is very likely that it would have continued to rise if the smoked salmon had not been withdrawn from the Dutch market. Nevertheless, the outbreak did not stop immediately after week 39. Possible reasons are the recall starting at the end of week 39, and an additional recall for products containing smoked salmon starting in week 40 . Furthermore, not everyone 
may have noticed the recall immediately or would have thrown away the smoked salmon already bought. Finally, because of the high number of cases personto-person transmission could have prolonged the outbreak. Before the start of the outbreak, zero to seven infections with $S$. Thompson per year were confirmed at the RIVM. Comparison of the PFGE of isolates prior to the outbreak revealed a different pattern compared to the outbreak strain. Although the strain appeared to be new in the Netherlands, several European countries had previously reported cases affected by a strain of similar pattern, including an outbreak in Norway and Sweden in 2004 [6]. Therefore, the strain does not appear to be new, even though it is unknown how well PFGE discriminates between the different $S$. Thompson strains.

Salmon is a rare cause of foodborne outbreaks of salmonellosis. Two outbreaks of $S$. Montevideo occurred in 1984 in a restaurant in the United Kingdom due to salmon, most likely contaminated by personnel after the cooking process [15]. Further, two different outbreaks of $S$. Enteritidis occurred after consumptions of salmon in 1999 in Denmark and in 2000 in the US, however in both outbreaks salmon dishes also contained eggs which could have been the cause of the outbreaks $[16,17]$. Reports of outbreaks due to $S$. Thompson are also scarce, and have not been linked to salmon before [5-9]. The cause of the current outbreak of $S$. Thompson was determined to be smoked salmon, based on the epidemiological case-control analyses, food investigation and product tracing, and microbiological confirmation. It is the largest outbreak of salmonellosis ever recorded in the Netherlands. The temporary closure of the Greek production site and recall of the smoked salmon prevented further cases. This outbreak showed that close collaboration between diagnostic laboratories, regional public health services, the national institute for public health and the food safety authorities is essential in outbreak investigations. Furthermore, outbreak investigations should start with an extensive questionnaire, as an outbreak can have an unexpected source.

\section{Acknowledgements}

We acknowledge the cases and controls, the officers from the public health services, physicians and microbiologists whose collaboration made this investigation possible. We thank Henny Maas, Anjo Verbruggen, Thijs Bosch and Kim van der Zwaluw for their technical assistance in the laboratory. Furthermore, we thank the colleagues of the NVWA involved in the recall (both laboratory and inspectors), and Corien Swaan, Harald Wychgel and Rody Zuidema (Centre for Infectious Disease Control, RIVM, Bilthoven) for their assistance in managing the outbreak. We thank Eva Gort and the colleagues of the Centre for Infectious Disease Control for their assistance in calling laboratories and regional public health services. Finally, we thank Eija Trees (Enteric Diseases Laboratory Branch, DFWED, NCEZID, CDC, Atlanta) for performing confirmatory PFGE on the Dutch $S$. Thompson.
Conflict of interest

None declared.

Authors' contributions

IF and $\mathrm{AH}$ coordinated the epidemiological part of the outbreak investigation, and collected, analysed and interpreted the data. IF drafted the manuscript. AdJ, and KN coordinated the food investigation part, and collected and interpreted the food-related data. DH and GvV carried out the food investigation. $\mathrm{MH}$ and $\mathrm{DN}$ coordinated the microbiological part of the outbreak investigation, and collected and analysed the Salmonella isolates. RdJ participated as advisor in the investigation. PvB and HvdK coordinated the internal and external communication about the outbreak and the investigation. WvP supervised the outbreak investigation and participated in the interpretation of the data. All authors participated in editing the manuscript, and read and approved the final manuscript.

\section{References}

1. Havelaar AH, Haagsma JA, Mangen MJ, Kemmeren JM, Verhoef LPB, Vijgen SMC, et al. Disease burden of foodborne pathogens in the Netherlands, 2009. Int J Food Microbiol. 2012;156(3):231-8. http://dx.doi.org/10.1016/j. ijfoodmicro.2012.03.029

2. Graveland H, Roest HJ, Stenvers O, Valkenburgh S, Friesema I, Van der Giessen J, et al. Staat van zoönosen 2012 [State of zoonoses]. Bilthoven: National Institute for Public Health and the Environment (RIVM); 2013. Dutch.

3. van Pelt W, Mevius D, Stoelhorst HG, Kovats S, van de Giessen AW, Wannet W, et al. A large increase of Salmonella infections in 2003 in The Netherlands: hot summer or side effect of the avian influenza outbreak? Euro Surveill. 2004;9(7):pii=473.

4. Van Duynhoven YT, Isken LD, Borgen K, Besselse M, Soethoudt K, Haitsma O, et al. A prolonged outbreak of Salmonella Typhimurium infection related to an uncommon vehicle: hard cheese made from raw milk. Epidemiol Infect. 2009;137(11):1548-57. http://dx.doi.org/10.1017/ So950268809002337

5. Campbell JV, Mohle-Boetani J, Reporter R, Abbott S, Farrar J, Brandl M, et al. An outbreak of Salmonella serotype Thompson associated with fresh cilantro. J Infect Dis. 2001;183(6):984-7. http://dx.doi.org/10.1086/319254

6. Nygard K, Lassen J, Vold L, Andersson Y, Fisher I, Löfdahl S, et al. Outbreak of Salmonella Thompson infections linked to imported rucola lettuce. Foodborne Pathog Dis. 2008;5(2):16573. http://dx.doi.org/10.1089/fpd.2007.0053

7. Kimura AC, Palumbo MS, Meyers H, Abbott S, Rodriguez $\mathrm{R}$, Werner SB. A multi-state outbreak of Salmonella serotype Thompson infection from commercially distributed bread contaminated by an ill food handler. Epidemiol Infect. 2005;133(5):823-8. http://dx.doi.org/10.1017/ So950268805004127

8. Shapiro R, Ackers ML, Lance S, Rabbani M, Schaefer L, Daugherty J, et al. Salmonella Thompson associated with improper handling of roast beef at a restaurant in Sioux Falls, South Dakota. J Food Prot. 1999;62(2):118-22.

9. Wright HA, Norval J, Orr A. Salmonella Thompson gastroenteritis; report of two outbreaks. BMJ. 1957;2(5036):69-71. http://dx.doi.org/10.1136/bmj.2.5036.69

10. Friesema I, de Jong A, Fitz James I, Heck M, van den Kerkhof I, Notermans D, et al. Outbreak of Salmonella Thompson in the Netherlands since July 2012. Euro Surveill. 2012;17(43): $\mathrm{pii}=20303$

11. van Pelt W, de Wit MA, Wannet WJ, Ligtvoet EJ, Widdowson MA, van Duynhoven YT. Laboratory surveillance of bacterial gastroenteric pathogens in The Netherlands, 1991-2001. Epidemiol Infect. 2003;130(3):431-41.

12. World Health Organization collaborating centre for reference and research on Salmonella. Antigenic formulae of the Salmonella serovars. Paris: Institut Pasteur; 2007.

13. International P. One-Day (24-28 h) Standardized Laboratory Protocol for Molecular Subtyping of Escherichia coli $0_{157} \mathrm{H}_{7}$, Salmonella serotypes, Shigella sonnei, and Shigella flexneri by Pulsed Field Gel Electrophoresis (PFGE). Atlanta: Centers for Disease Prevention and Control; 2009. [Accessed 12 Oct 
2012]. Available from: http://www.pulsenetinternational.org/ protocols/

14. Onderzoeksraad voor Veiligheid. Salmonella in gerookte zalm. [Salmonella in smoked salmon]. Den Haag:

Onderzoeksraad voor Veiligheid; 2013. Dutch. Available from: http://www.onderzoeksraad.nl/uploads/phasedocs/450/4e4564b46952rapport-salmonella-nl-web.pdf

15. Cartwright KA, Evans BG. Salmon as a food-poisoning vehicle--two successive Salmonella outbreaks. Epidemiol Infect. 1988;101(2):249-57. http://dx.doi.org/10.1017/ So950268800054169

16. Locht H, Mølbak K, Krogfelt KA. High frequency of reactive joint symptoms after an outbreak of Salmonella enteritidis. J Rheumatol. 2002;29(4):767-71.

17. Jones RC, Gerber SI, Diaz PS, Williams LL, Dennis SB, Parish $\mathrm{ES}$, et al. Intensive investigation of bacterial foodborne disease outbreaks: proposed guidelines and tools for the collection of dose-response data by local health departments. J Food Prot. 2004;67(3):616-23. 